\title{
Association of Serum Lipid Levels with Parkinson's Disease: A Case-Control Study
}

\author{
HUQ MR ${ }^{1}$, HANNAN MA $^{2}$, HABIB MA ${ }^{3}$, ISLAM MR ${ }^{4}$, MIAH MBA ${ }^{5}$, AHMED A ${ }^{6}$, SARKER I , \\ ISLAM MZ ${ }^{8}$, AGARWALLAAK $^{9}$, HASAN M $^{10}$, ISLAM MS ${ }^{11}$
}

\begin{abstract}
:
Background: Parkinson's disease (PD) is a common neurodegenerative disorder. Many hypotheses have been put forward for PD pathogenesis including role of lipid metabolism. Methods: This case control study was carried out in the department of neurology, Bangabandhu Sheikh Mujib Medical University (BSMMU), Dhaka, from April 2018 to September 2019. A total of 90 persons were enrolled as study population after satisfying inclusion and exclusion criteria. Among them, 42 PD patients were grouped as cases and 48 healthy persons were controls. Results: We have compared the mean ( $\pm S D)$ value $(\mathrm{mg} / \mathrm{dl})$ of serum lipid variables among the cases and the controls. Serum total cholesterol in PD patients was found lower than that of control group (176.88 $\pm 41.12 \mathrm{vs}$ $209.27 \pm 43.69 \mathrm{mg} / \mathrm{dl})$ which was statistically significant $(p=0.001)$ and mean $( \pm S D)$ value $(\mathrm{mg} / \mathrm{dl})$ of serum $L D L-C$ in $P D$ patients was also found significantly lower than that of control group (107.44 \pm 39.04 vs $127.40 \pm 37.83 \mathrm{mg} / \mathrm{dl}$, $p=0.017)$. Serum TG levels were also significantly lower among PD patients than that of controls $(152.40$ \pm 77.86 vs $206.71 \pm 94.76 \mathrm{mg} / \mathrm{dl}, p=0.04)$. Serum high-density lipoprotein cholesterol (HDL-C) levels were statistically similar among cases and controls (39.81 \pm 9.79 vs $39.33 \pm 12.21 \mathrm{mg} / \mathrm{dl}, p=0.840$ ). Conclusion: There is an association between low serum TC, LDL-C and TG levels with $P D$. Further prospective studies are necessary to confirm the association.
\end{abstract}

Key words: Parkinson's disease, lipid, cholesterol, triglyceride etc.

\section{Introduction:}

Parkinson's disease (PD) is a progressive degenerative disease of brain, characterized by resting tremor, rigidity, bradykinesia and postural instability. In 2016, 6.1 million individuals worldwide had Parkinson's disease, of whom 2.9 million $(47.5 \%)$ were women and 3.2 million $(52.5 \%)$ were men $^{1}$. There were approximately 54198 (42488 to 67532) cases of PD in Bangladesh in $2016^{1}$.

Nevertheless, the pathogenesis of PD is yet unknown. Although a few PD cases are due to several known genetic mutations, the disorder is largely idiopathic and likely involves interactions of the genome and the environment.

Cholesterol is an important constituent of cell membranes and plays a crucial role in the formation of the plasma membrane and signaling. Many neurodegenerative diseases are characterized by impaired cholesterol turnover in the brain. However, at which stage the cholesterol biosynthetic pathway is altered and how this contributes to pathogenesis remain unknown ${ }^{2}$. Several recent findings also

1. Dr. Muhammad Rezeul Huq, Resident, Dept. of Neurology, BSMMU, Dhaka.

2. Prof. (Dr.) MA Hannan, Professor, Dept. of Neurology, BSMMU, Dhaka.

3. Dr. Md. Ahsan Habib, Associate Professor, Dept. of Neurology, BSMMU, Dhaka.

4. Prof. (Dr.) Md. Rafiqul Islam, Professor and Chairman, Dept. of Neurology, BSMMU, Dhaka.

5. Dr. Md Bahadur Ali Miah, Associate Professor, Dept. of Neurology, BSMMU, Dhaka.

6. Dr. Anis Ahmed. Assistant Professor, Dept. of Neurology, BSMMU, Dhaka.

7. Dr. Imran Sarker, Assistant Professor (CC), Dept. of Clinical Neurology, NINS\&H, Dhaka

8. Dr. Md Zahidul Islam, Resident, Dept. of Neurology, BSMMU, Dhaka.

9. Dr. Ajay Kumar Agarwalla, Resident, Dept. of Neurology, BSMMU, Dhaka.

10. Dr. Mehedi Hasan, Resident, Dept. of Neurology, BSMMU, Dhaka.

11. Md. Shofikul Islam, Resident, Dept. of Neurology, BSMMU, Dhaka. 
suggest a role of lipid and cholesterol metabolism in Parkinson's disease pathogenesis ${ }^{3}$. High level of cholesterol may reduce the prevalence of $P D$ by promoting the neuroprotective effect of CoQ10 since serum cholesterol is an important determinant of CoQ10 circulation 4 .

Another possible mechanism behind association of serum lipid level with PD includes the role of APOE gene. A recent systematic review, however, demonstrated that it is the õ2 allele that is positively associated with higher prevalence of sporadic $\mathrm{PD}^{5}$. õ2 allele also has been associated with lower plasma LDL-C 6 . As APOE õ2 allele is associated with both $\mathrm{PD}$ and low plasma LDL-C, PD patients may have lower plasma LDL-C level. It was suggested in one study that these changes may be related to the reduced sympathetic activity in PD due to autonomic dysfunction. In that study, authors have found low TG levels in PD patients significantly in comparison to control group which might be consistent with reduced catecholamine and cortisol production?

The above mentioned evidences led us to formulate hypothesis that lower cholesterol may be associated with PD. Many studies have focused on the relationships between lipid profiles and the risk, as well as on the progression of PD. However, the results were not completely consistent with each other. Further studies are required to clarify the association of serum cholesterol level and neurodegenerative diseases including PD.

\section{Methods:}

After obtaining ethical clearance from Institutional Review Board (IRB) of BSMMU, patients having features of PD, diagnosed by MDS Clinical Diagnostic Criteria for PD, $2015^{8}$ and fulfilling the inclusion and exclusion criteria were selected as case group. 42 patients were taken as cases; and 48 age and sex matched healthy persons were taken as controls who fulfilled the inclusion and exclusion criteria for control group. Sample size was calculated using mean and standard deviation of TC and LDL-C from a previous study using stastical formula at $5 \%$ level of significance and $90 \%$ power $^{9}$. Demographic variables were age, sex, smoking status, presence of hypertension and body mass index (BMI). Serum lipid levels (TG, LDL-C, HDL-C, TG) were taken as laboratory variables. Informed written consent was taken from each patient or his/her attendant (both case and control group). After taking proper history, physical and neurological examinations, fasting serum lipid profile and other relevant investigations were done. Proper diagnosis and treatment were ensured for each person of case group. For fasting lipid profile, venous blood was collected under sterile conditions using a disposable syringe between 8.00 to 10.00 a.m. after overnight fasting (12 hours). The serum total cholesterol (TC), high density lipoprotein cholesterol (HDL-C) and triglyceride (TG) levels were measured by using Beckman Coulter-A680 analyzer machine and low density lipoprotein Cholesterol (LDL-C) level was calculated by using Friedewald's equation from laboratory of the department of biochemistry, BSMMU. Quality control (QC) was ensured by doing updated calibration and by checking QC curve shown in the autoanalyzer.

The medical records, demographics, clinical and laboratory records of the all patients were examined. All the data were checked and edited after collection. At the end of data collection, the mean and standard deviation of serum levels of total cholesterol, HDL-C, LDL-C and TG were calculated for both case and control group. Quantitative data were analyzed by $t$ test and qualitative data including sex, occupation, educational levels were analyzed by $\div^{2}$ test. $P$ value $<0.05$ was considered as significant. In the case group, the correlation among serum cholesterol levels with disease duration was made by the Pearson's bivariate correlation test. Finally, to assess the relative significance of potential etiological variable, logistic regression was used for risk assessment. Odds ratios and 95\% Confidence Intervals were calculated. All data processing statistical analysis were done by SPSS (Statistical Package for the Social Sciences) software (version 25.0).

\section{Results:}

Total 42 patients of Parkinson's disease were taken as cases and 48 age and sex matched healthy 
persons were taken as controls. Results were expressed as mean $\pm \mathrm{SD}$. Unpaired ' $t$ ' test was done as a test of significance. $\mathrm{P}<0.05$ was considered as significant. Mean age of all patients was $59.43 \pm 11.34$ years and mean age of control was $56.38 \pm 12.92$ years. Distribution was statistically similar across cases and controls $(p>0.05)$. Majority patients were male $(73.8 \%)$ with 2.6:1 male-female ratio.Sex distribution was also similar across cases and controls $(p>0.05)$. Serum TC, LDL-C and TG levels were significantly lower among PD patients than that of controls $(p<0.05)$. Serum HDL-C levels were statistically similar among cases and controls. Logistic regression analysis was done to determine the Odds of developing PD in relation to different quartiles of cholesterol level adjusted for age, sex, BMI, HTN and smoking status. The lower the level of TC the higher the odds of developing PD.

Table-I

Sex distribution of participants $(N=90)$

\begin{tabular}{lcc}
\hline Sex & $\begin{array}{c}\text { Case }(n=42) \\
\text { No. }(\%)\end{array}$ & $\begin{array}{c}\text { Control }(n=48) \\
\text { No. }(\%\end{array}$ \\
\hline Male & $31(73.8)$ & $35(72.9)$ \\
Female & $11(26.2)$ & $13(27.1)$ \\
\hline
\end{tabular}

The lowest quartiles of LDL-C and TG also showed significant chance of developing Parkinson's disease. HDL-C didn't show any significant association with PD. Pearson's bivariate correlation was performed to asess correlation of serum lipid profile with duration of Parkinson's disease.None of the serum lipid profile variables showed any significant correlation with duration of disease.

Table-II

Distribution of participants according to their serum lipid profile $(N=90)$

\begin{tabular}{lccc}
\hline Lipid profile & $\begin{array}{c}\text { Case }(\mathrm{n}=42) \\
(\mathrm{mean} \pm \mathrm{SD} \text { in } \mathrm{mg} / \mathrm{dl})\end{array}$ & $\begin{array}{c}\text { Control }(\mathrm{n}=48) \\
(\text { mean } \pm \text { SD in mg/dl) }\end{array}$ & p-value \\
\hline Total Cholesterol (TC) & $176.88 \pm 41.12$ & $209.27 \pm 43.69$ & 0.001 \\
Low Density Lipoprotein (LDL-C) & $107.44 \pm 39.04$ & $127.40 \pm 37.83$ & 0.017 \\
High Density Lipoprotein (HDL-C) & $39.81 \pm 9.79$ & $39.33 \pm 12.21$ & 0.840 \\
Triglyceride (TG) & $152.40 \pm 77.86$ & $206.71 \pm 94.76$ & 0.004 \\
\hline
\end{tabular}

Results were expressed as mean \pm SD. Unpaired ' $t$ ' test was done as a test of significance. $P<0.05$ was considered as significant.

Table-III

Correlation of serum lipid profile with duration of Parkinson's disease $(N=42)$

\begin{tabular}{lccc}
\hline $\begin{array}{l}\text { Correlation of duration of } \\
\text { disease with PD }\end{array}$ & $\begin{array}{l}\text { Pearson's } r \\
\text { (correlation } \\
\text { coefficient) }\end{array}$ & $\begin{array}{c}\mathrm{r}^{2} \\
\text { (coefficient of } \\
\text { determination) }\end{array}$ & p-value \\
\hline Total Cholesterol (TC) & 0.046 & 0.002 & 0.772 \\
Low Density Lipoprotein (LDL-C) & 0.052 & 0.003 & 0.743 \\
High Density Lipoprotein (HDL-C) & -0.225 & 0.051 & 0.153 \\
Triglyceride (TG) & -0.295 & 0.087 & 0.058 \\
\hline
\end{tabular}

Pearson's bivariate correlation was performed to compare between two groups. None of the serum lipid profile variables showed a significant correlation with duration of disease. 
Table-IV

Odds ratios of Parkinson's disease according to quartiles of serum cholesterol concentrations $(N=90)$

\begin{tabular}{|c|c|c|c|c|c|c|c|c|}
\hline \multirow{2}{*}{$\begin{array}{l}\text { Serum } \\
\text { cholesterol }\end{array}$} & \multirow{2}{*}{$\begin{array}{c}\text { Unadjusted } \\
\text { OR }\end{array}$} & \multicolumn{2}{|c|}{$95 \% \mathrm{Cl}$} & \multirow{2}{*}{$\begin{array}{c}P \\
\text { value }\end{array}$} & \multirow{2}{*}{$\begin{array}{c}\text { Adjusted * } \\
\text { OR }\end{array}$} & \multicolumn{2}{|c|}{$95 \% \mathrm{Cl}$} & \multirow[t]{2}{*}{$P$ value } \\
\hline & & $\begin{array}{l}\text { Lower } \\
\text { bound }\end{array}$ & $\begin{array}{l}\text { Upper } \\
\text { bound }\end{array}$ & & & $\begin{array}{l}\text { Lower } \\
\text { bound }\end{array}$ & $\begin{array}{l}\text { Upper } \\
\text { bound }\end{array}$ & \\
\hline \multicolumn{9}{|l|}{$\mathrm{TC}(\mathrm{mg} / \mathrm{dl})$} \\
\hline $224-342$ & 1 & & & & 1 & & & \\
\hline $193-223$ & 4.180 & 1.133 & 15.419 & 0.032 & 7.734 & 1.653 & 36.174 & 0.009 \\
\hline $160-192$ & 2.923 & 0.809 & 10.561 & 0.102 & 4.92 & 1.136 & 21.307 & 0.033 \\
\hline $88-159$ & 10.133 & 2.600 & 39.499 & 0.001 & 12.05 & 2.631 & 55.184 & 0.001 \\
\hline \multicolumn{9}{|c|}{ LDL-C (mg/dl) } \\
\hline $145-265$ & 1 & & & & 1 & & & \\
\hline $115-144$ & 1.259 & 0.377 & 4.204 & 0.708 & 1.387 & 0.366 & 5.262 & 0.63 \\
\hline $87-114$ & 1.574 & 0.491 & 5.046 & 0.445 & 2.297 & 0.613 & 8.603 & 0.217 \\
\hline $40-86$ & 4.048 & 1.21 & 13.538 & 0.023 & 3.957 & 1.059 & 14.777 & 0.041 \\
\hline \multicolumn{9}{|c|}{ HDL-C (mg/dl) } \\
\hline $18-32$ & 1 & & & & 1 & & & \\
\hline $33-38$ & 0.364 & 0.106 & 1.249 & 0.108 & 0.356 & 0.094 & 1.347 & 0.128 \\
\hline $38-45$ & 2.494 & 0.745 & 8.342 & 0.138 & 2.791 & 0.758 & 10.278 & 0.123 \\
\hline $46-76$ & 0.893 & 0.268 & 2.97 & 0.853 & 0.62 & 0.158 & 2.427 & 0.493 \\
\hline \multicolumn{9}{|l|}{$\mathrm{TG}(\mathrm{mg} / \mathrm{dl})$} \\
\hline $220-502$ & 1 & & & & 1 & & & \\
\hline $167-219$ & 2.877 & 0.8 & 10.35 & 0.106 & 1.635 & 0.379 & 7.057 & 0.51 \\
\hline $113-166$ & 2.354 & 0.635 & 8.725 & 0.2 & 1.986 & 0.493 & 8.000 & 0.335 \\
\hline $61-112$ & 11.56 & 2.822 & 47.356 & 0.001 & 11.391 & 2.42 & 53.614 & 0.002 \\
\hline
\end{tabular}

*Adjusted for age, sex, BMI, HTN and smoking status

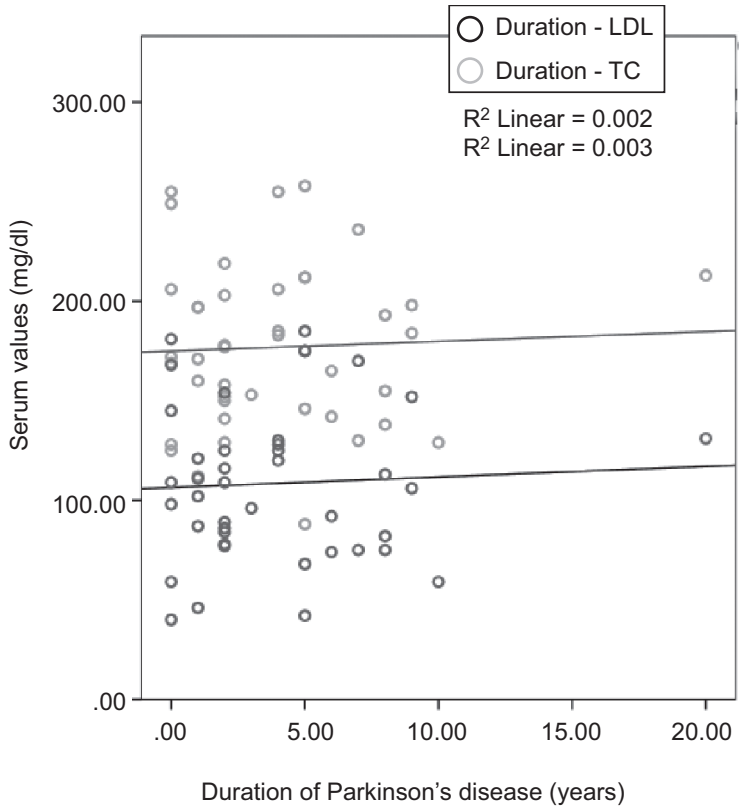

Figure 1: Scatter diagram showing relationship of TC (green circles) and LDL (blue circles) with duration of $P D\left(r^{2}\right.$ linear $=$ coefficient of determination)

\section{Discussion:}

Parkinson's disease is a common neurodegenerative disease having no definite treatment. Increasing evidence suggests that serum lipid levels are associated with PD, even may be related with pathogenesis of PD. This casecontrol study was carried out primarily with an aim to find out the association of serum lipid levels in patients with Parkinson's disease.

In this study mean $\pm S D$ values of serum total cholesterol and low density lipoprotein cholesterol level were reduced in PD patients as compared to those of control group (176.88 \pm 41.12 vs 209.27 $\pm 43.69 \mathrm{mg} / \mathrm{dl}$ and $107.44 \pm 39.04$ vs 127.40 $\pm 37.83 \mathrm{mg} / \mathrm{dl}$ respectively) which were statistically significant $(p<0.05)$. Serum TG levels were also significantly lower among PD patients than that of controls $(152.40 \pm 77.86$ vs $206.71 \pm 94.76, p=$ 0.04). Serum high-density lipoprotein cholesterol (HDL-C) levels were statistically similar among cases and controls (39.81 \pm 9.79 vs $39.33 \pm 12.21$, $p=0.840$ ). 
It was consistent with other case-control studies ${ }^{7,9-}$ 13. For example, in one study ${ }^{13}$ the mean levels of total cholesterol, LDL-C and TG were significantly lower in the PD patients than in the controls $(4.5 \pm$ $0.9 \mathrm{mmol} / \mathrm{L}$ vs. $5.0 \pm 0.9 \mathrm{mmol} / \mathrm{L}, \mathrm{p}<0.001 ; 2.5 \pm$ $0.7 \mathrm{mmol} / \mathrm{L}$ vs. $2.9 \pm 0.7 \mathrm{mmol} / \mathrm{L}, p<0.001 ; 1.2 \pm$ $0.8 \mathrm{mmol} / \mathrm{L}$ vs. $1.5 \pm 0.8 \mathrm{mmol} / \mathrm{L}, p<0.001$; respectively. Like our study, most of the study didn't find any association of serum high-density lipoprotein cholesterol (HDL-C) with PD. All these studies including this one support the hypothesis that low serum lipids levels(TC, LDL-C, TG) could play an important role in the pathogenesis of Parkinson's disease.

We used a logistic regression analysis to get the effect of serum total cholesterol and low density lipoprotein cholesterol level on Parkinson's disease. Fasting concentrations of total cholesterol and LDL-C were divided into quartiles. Odds ratios (ORs) and 95\% confidence intervals (Cls) were estimated by logistic regression, adjusting for age, gender, smoking, BMI and presence of HTN. The lower the level of TC the higher odds of developing PD. Unadjusted odds ratios were 4.180, 2.923, 10.133 and adjusted odd ratios were $7.734,4.92$, 12.05 which were statistically significant $(p<0.05)$. The lowest quartile of LDL-C also showed significant chance of developing Parkinson's disease. Unadjusted odds ratios were 1.259, 1.574, 4.048 and adjusted odds ratios were 5.262, 8.603, 14.777; the odds ratio of the lowest quartile was statistically significant $(p<0.05)$. The lowest quartile of TG also showed significant chance of developing Parkinson's disease. Unadjusted odds ratios were $2.877,2.354,11.56$ and adjusted odds ratios were $1.635,1.986,11.391$; the odds ratio of lowest quartile was statistically significant $(p<0.05)$. HDL$C$ didn't show any significant association with PD.

It was consistent with some other recent studies $7,10,13$. Like current study, fasting concentrations of TC and LDL-C were divided into quartiles in another case-control study ${ }^{10}$. The risk of PD was significantly lower in the third tertile of cholesterol, triglyceride and total lipid levels than the first tertile in another study ${ }^{7}$. None of the serum lipid profile variables showed a significant correlation with duration of disease. Pearson's $r$ (correlation coefficient) and $p$ value for TC were 0.046 and 0.772 respectively; for LDL-C Pearson's $r$ (correlation coefficient) and $p$ value were 0.052 and 0.743 respectively which indicated no significant correlation. Serum TG and HDL-C showed negative but insignificant correlation. Also in a previous study, they did not find any significant correlations among TG, cholesterol, LDL-C, HDL$C$ and disease duration $(p>0.05)$. It was found previously that PD patients have decreased incidence of stroke and myocardial infarction than healthy persons ${ }^{14}$. Low lipid TC, LDL-C and TG levels in PD patients may protect PD patients from adverse cardiovascular events.

\section{Conclusion :}

The present study showed that serum total cholesterol, low density lipoprotein cholesterol levels and triglyceride levels were significantly lower in PD patients in comparison to control group. This may be interpreted as linking lower TC, LDL-C and TG levels having association with PD. It seems timely and critical to reevaluate our results in larger scale in our population, and to seek the underlying mechanism that may be of potential importance in understanding the etiology of PD. Besides, it has public health implications, which may even lead to some changes in current guidelines recommending strict control of serum lipid profile.

\section{References:}

1. Dorsey ER, Elbaz A, Nichols E, Abd-Allah F, Abdelalim A, Adsuar JC, Ansha MG, Brayne C, Choi JY, Collado-Mateo D, Dahodwala N. Global, regional, and national burden of Parkinson's disease, 1990-2016: a systematic analysis for the Global Burden of Disease Study 2016. The Lancet Neurology. 2018 Nov 1;17(11):939-53.

2. Petrov AM, Kasimov MR, Zefirov AL. Cholesterol in the pathogenesis of Alzheimer's, Parkinson's diseases and autism: link to synaptic dysfunction. Acta

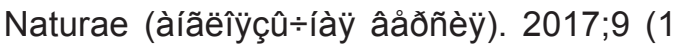
(32).

3. Hu G, Antikainen R, Jousilahti P, Kivipelto M, Tuomilehto J. Total cholesterol and the risk of Parkinson disease. Neurology. 2008 May 20;70(21):1972-9. 
4. Kaikkonen J, Nyyssönen K, Tuomainen TP, Ristonmaa U, Salonen JT. Determinants of plasma coenzyme Q10 in humans. FEBS letters. 1999 Jan 29;443(2):163-6.

5. Huang $X$, Chen PC, Poole C. APOE-å2 allele associated with higher prevalence of sporadic Parkinson disease. Neurology. 2004 Jun 22;62(12):2198-202.

6. Bennet AM, Di Angelantonio E, Ye Z, Wensley F, Dahlin A, Ahlbom A, Keavney B, Collins R, Wiman B, de Faire U, Danesh J. Association of apolipoprotein E genotypes with lipid levels and coronary risk. Jama. 2007 Sep 19;298(11):1300-11.

7. Scigliano G, Musicco M, Soliveri P, Piccolo I, Ronchetti G, Girotti F. Reduced risk factors for vascular disorders in Parkinson disease patients: a case-control study. Stroke. 2006 May 1;37(5):1184-8.

8. Postuma RB, Berg D, Stern M, Poewe W, Olanow CW, Oertel W, Obeso J, Marek K, Litvan I, Lang AE, Halliday G. MDS clinical diagnostic criteria for Parkinson's disease. Movement Disorders. 2015 Oct;30(12):1591601.

9. Cereda E, Cassani E, Barichella M, Spadafranca A, Caccialanza R, Bertoli S, Battezzati A, Pezzoli G. Low cardiometabolic risk in Parkinson's disease is independent of nutritional status, body composition and fat distribution. Clinical nutrition. 2012 Oct 1;31(5):699-704.

10. Huang $\mathrm{X}$, Chen $\mathrm{H}$, Miller WC, Mailman R, Woodard JL, Chen P. Lower LDL cholesterol levels are associated with Parkinson's disease: a case control study. Mov Disord. 2007;22(3):377-81.

11. Miyake $\mathrm{Y}$, Tanaka K, Fukushima W, Sasaki S, Kiyohara C, Tsuboi Y, Yamada T, Oeda T, Miki T, Kawamura N, Sakae N. Case-control study of risk of Parkinson's disease in relation to hypertension, hypercholesterolemia, and diabetes in Japan. Journal of the neurological sciences. 2010 Jun 15;293(1-2):82-6.

12. Ikeda K, Nakamura $\mathrm{Y}$, Kiyozuka T, Aoyagi J, Hirayama T, Nagata R, Ito $\mathrm{H}$, Iwamoto $\mathrm{K}$, Murata K, Yoshii Y, Kawabe K. Serological profiles of urate, paraoxonase-1, ferritin and lipid in Parkinson's disease: changes linked to disease progression. Neurodegenerative Diseases. 2011;8(4):252-8.

13. Guo X, Song W, Chen K, Chen X, Zheng Z, Cao B, Huang R, Zhao B, Wu Y, Shang HF. The serum lipid profile of Parkinson's disease patients: a study from China. International Journal of Neuroscience. 2015 Nov 2;125(11):838-44.

14. Nataraj A, Rajput AH. Parkinson's disease, stroke, and related epidemiology. Movement disorders: official journal of the Movement Disorder Society. 2005 Nov;20(11):1476-80. 